\title{
Risk of infection and transmission of SARS- CoV-2 among children and adolescents in households, communities and educational settings: A systematic review and meta-analysis
}

\author{
Omar $\operatorname{Irfan}^{1 *}$, \\ Jiang $\mathrm{Li}^{1 *}$, \\ Kun Tang ${ }^{1,2}$, \\ Zhicheng Wang ${ }^{2}$, \\ Zulfiqar A Bhutta ${ }^{1,3}$ \\ ${ }^{1}$ Centre for Global Child \\ Health, The Hospital for \\ Sick Children, Toronto, \\ Canada \\ ${ }^{2}$ Vanke School of Public \\ Health, Tsinghua \\ University, Beijing, China \\ ${ }^{3}$ Institute for Global \\ Health \& Development, \\ the Aga Khan University, \\ Karachi, Pakistan \\ *Joint first authors.
}

\section{Correspondence to:}

Zulfiqar A Bhutta Professor \& Co-Director, Centre for Global Child Health

Hospital for Sick Children 686 Bay Avenue Toronto, ON, M5G 0A4 Canada

\begin{abstract}
Background There is uncertainty with respect to SARS-CoV-2 transmission in children (0-19 years) with controversy on effectiveness of school-closures in controlling the pandemic. It is of equal importance to evaluate the risk of transmission in children who are often asymptomatic or mildly symptomatic carriers that may incidentally transmit SARS-CoV-2 in different settings. We conducted this review to assess transmission and risks for SARS-CoV-2 in children (by agegroups or grades) in community and educational-settings compared to adults.
\end{abstract}

Methods Data for the review were retrieved from PubMed, EMBASE, Cochrane Library, WHO COVID-19 Database, China National Knowledge Infrastructure (CNKI) Database, WanFang Database, Latin American and Caribbean Health Sciences Literature (LILACS), Google Scholar, and preprints from medRixv and bioRixv) covering a timeline from December 1, 2019 to April 1, 2021. Population-screening, contact-tracing and cohort studies reporting prevalence and transmission of SARS-CoV-2 in children were included. Data were extracted according to PRISMA guidelines. Meta-analyses were performed using Review Manager 5.3.

Results Ninety studies were included. Compared to adults, children showed comparable national (risk ratio $(\mathrm{RR})=0.87,95 \%$ confidence interval $(\mathrm{CI})=0.71-1.060$ and subnational $(\mathrm{RR}=0.81,95 \% \mathrm{CI}=0.66-1.01)$ prevalence in population-screening studies, and lower odds of infection in community/household contact-tracing studies (odds ratio $(O R)=0.62,95 \%$ $\mathrm{CI}=0.46-0.84)$. On disaggregation, adolescents observed comparable risk $(\mathrm{OR}=1.22,95 \%$ $\mathrm{CI}=0.74-2.04)$ with adults. In educational-settings, children attending daycare/preschools $(\mathrm{OR}=0.53,95 \% \mathrm{CI}=0.38-0.72)$ were observed to be at lower-risk when compared to adults, with odds of infection among primary $(\mathrm{OR}=0.85,95 \% \mathrm{CI}=0.55-1.31)$ and high-schoolers $(\mathrm{OR}=1.30,95 \% \mathrm{CI}=0.71-2.38)$ comparable to adults. Overall, children and adolescents had lower odds of infection in educational-settings compared to community and household clusters.

Conclusions Children ( $<10$ years) showed lower susceptibility to COVID-19 compared to adults, whereas adolescents in communities and high-schoolers had comparable risk. Risks of infection among children in educational-settings was lower than in communities. Evidence from school-based studies demonstrate it is largely safe for children ( $<10$ years) to be at schools, however older children (10-19 years) might facilitate transmission. Despite this evidence, studies focusing on the effectiveness of mitigation measures in educational settings are urgently needed to support both public health and educational policy-making for school reopening.

As of 5 April 2021, there have been 131.0 million confirmed COVID-19 cases and nearly 2.8 million confirmed deaths globally [1]. The response in countries worldwide has gone from an initial stage of strict lockdowns and business closures to variable periods of relaxation with social distancing, use of face masks and hand hygiene, and now vaccination roll outs for adults. During this period, daycare centers, schools and educational institutions were closed initially and then reopened 
at different stages. This has however, been a bone of much contention across the world with various countries adopting different measures. The global spread of variants of concern now threatens to reverse progress and disrupt the opening of the economy, commerce and education.

School closures are understandable. Children play an important role in the transmission of some respiratory infectious diseases and may suffer from more severe outcomes than adults, such as influenza [2,3], rendering school closures an effective public health policy in reducing the spread and influence of these diseases. This is especially true in novel pandemics where pharmaceutical interventions, such as vaccines, are not immediately available and delaying disease spread is a priority [3-6]. However, children and adolescents under 19 years of age comprise a small proportion of total reported COVID-19 cases (1\%-10\%) [7-9]. This group has been reported to present with a milder clinical course compared to adults infected with SARS-CoV-2, with more favorable outcomes in general [7,9-11].

To date, there is much controversy concerning the benefits of the ongoing and future closure of schools and other educational institutions in controlling the COVID-19 pandemic, as limited data on transmission of COVID-19 in educational settings is available [12-16]. It is of equal importance to evaluate the risk of susceptibility and transmission in children who are often asymptomatic or mildly symptomatic carriers, that may incidentally transmit SARS-CoV-2 in both educational and community settings, especially with the third wave of COVID-19 and newer variants spreading in many Countries crippling the health care system and economy.

We undertook a systematic review of the infection and transmission rates and risks of SARS-CoV-2 in children and adolescents in household, community and educational settings since the beginning of the pandemic, to help in understanding policy responses for safe school reopening for children of various ages.

\section{METHODS}

This systematic review is reported in accordance with the Preferred Reporting Items for Systematic Reviews and Meta-Analyses (PRISMA) reporting guidelines.

In this review, we focused on the following review objectives:

1-What is the overall risk of infection in children and adolescents compared to adults ( $>19$ years) from population screening and contact-tracing studies?

2-What are the odds of being an infected contact in children and adolescents compared to adults ( $>19$ years) in educational settings?

3-What is the risk of infection for children and adolescents in educational settings in comparison to that in communities?

\section{Literature search}

To investigate the risk of SARS-CoV-2 infection and transmission in children and adolescents and their potential contribution to transmission in various settings, we searched for national and subnational prevalence studies, and contact-tracing studies (CTS) from community/household clusters and educational settings.

Data for the review were retrieved from PubMed, EMBASE, Cochrane Library, WHO COVID-19 Database, China National Knowledge Infrastructure (CNKI) Database, WanFang Database, Latin American and Caribbean Health Sciences Literature (LILACS), Google Scholar, and "Living Evidence of COVID-19" (a database updated daily with published articles from PubMed and EMBASE and preprints from medRixv and bioRixv) covering a timeline from December 1, 2019 to April 1, 2021. Preprints from ChinaXiv (http://www.chinaxiv. org/home.htm) were also searched. Complementary searches were conducted by manually searching the national public health websites, and the John Hopkins Humanitarian Health Resource. The reference lists of all retrieved articles were examined as well. There was no language restriction applied for the search. The search terms applied for each research question and the specific search strategies for PubMed and other databases are provided in Table S1 in the Online Supplementary Document.

The search results from various databases were uploaded into Covidence Systematic Review Software (Veritas Health Innovation 2016, Melbourne, Australia) for screening.

\section{Inclusion and exclusion criteria}

We included population screening studies investigating the age-specific prevalence of SARS-CoV-2 infections, contact-tracing and cohort studies reporting the incidence and attack rate (number of infections secondary to a suspected close contact) of children (0-9 years) and adolescents (10-19 years old) compared to adults, case 
series presenting direct evidence of COVID-19 cases transmitted by SARS-CoV-2 positive children compared to adults, and data from national public health websites and official government reports, when available. We excluded review articles, opinions, viewpoints and communication letters (if not presenting data on number of infections or attack rate of SARS-CoV-2) and modeling studies were also excluded. Studies that did not report the number of infections or attack rate of SARS-CoV-2, and studies with possible duplications of cases (eg, overlapping time periods within the same institutions/cities/countries) were also excluded.

\section{Study screening}

Two review authors independently reviewed each title and abstract from the search results. Upon obtaining the full text, two reviewers independently screened the full text and decided whether to include or exclude the study, in accordance with the criteria specified previously. Any disagreements were resolved by independent review by a third author.

\section{Data extraction}

The following data were extracted from each study using standardized data abstraction forms: authors, country, study type, study period and its relationship with the epidemic curve in the country/area and school closure/ reopen status, study setting (household, community, daycare, primary or secondary school; other mitigation measures if any), case definition (index case, primary case, secondary case), testing methods, contact-tracing methods, sampling method, number of infected children and/or adults (specified whether or not student-contacting staff) and total number of students and staff in the educational setting (or reported attack rate).

\section{Meta-analysis and qualitative synthesis}

For each dichotomous outcome, the weighted mean prevalence and 95\% confidence interval (CI) was calculated. The meta-analyses were performed using Review Manager 5.3 adopting the random-effects models. Pooled risk ratios (RR) between children and adults were presented in both national and subnational prevalence studies with disaggregation into active infection and past infection indicated by PCR testing and antibodies seroprevalence, respectively. The pooled odds ratios (OR) of children being infected in households were presented and disaggregated by children ( $<10$ years) and adolescent (10-19 years), and school operational status (open/partially open or closed) in the region/Country. The odds of contracting infection in children compared to adults in schools and daycare centers were also analyzed. Total number of children and adolescents tested and diagnosed with COVID-19 were computed separately for communities and educational settings to calculate the odds ratio (OR) of risk of infection in educational settings compared to community settings. Statistical heterogeneity across studies was evaluated by calculating the $\mathrm{I}^{2}$ statistic. $\mathrm{I}^{2}$ values equal to or above $50 \%$ were considered as "significant" heterogeneity in this study. Additionally, the $\chi^{2}$ test for heterogeneity was performed and the forest plot was visually inspected to assess the degree of overlap between the CIs of included studies. The characteristics, biases, and results of the included studies were summarized narratively. For studies included but not eligible for meta-analysis due to a lack of sufficient data, we also qualitatively synthesized the results to present a full picture.

\section{Assessment of methodological quality and risk of bias}

Two independent reviewers assessed each included study for methodological quality. A quality assessment tool was adopted from the National Heart, Lung, and Brain Institute (NHLBI) and Research Triangle Institute International [17] for observational studies, where are as the quality of prevalence studies was assessed using a critical appraisal checklist for prevalence studies [18]. Study quality was scored on basis of clear study objectives, case definition, consecutive inclusion of cases, sample sizes, comparability of included patients, measurement of outcomes, length of follow-up, and appropriately defined statistical methods and results. However, studies were not excluded based on study quality. Studies with score 6-8 were considered to be good quality, 4-5 considered fair quality and $<4$ considered poor quality.

\section{RESULTS}

The systemic literature search yielded 3700 results during the search dates. Of these, 117 studies were examined in full text and 90 were included in the final analysis after addition of 3 studies from other resources (Figure 1). The characteristics of included studies were summarized in Table $S 2$ in the Online Supplementary Document. Thirty studies were excluded because they either presented overlapping data, provided little age-dis- 

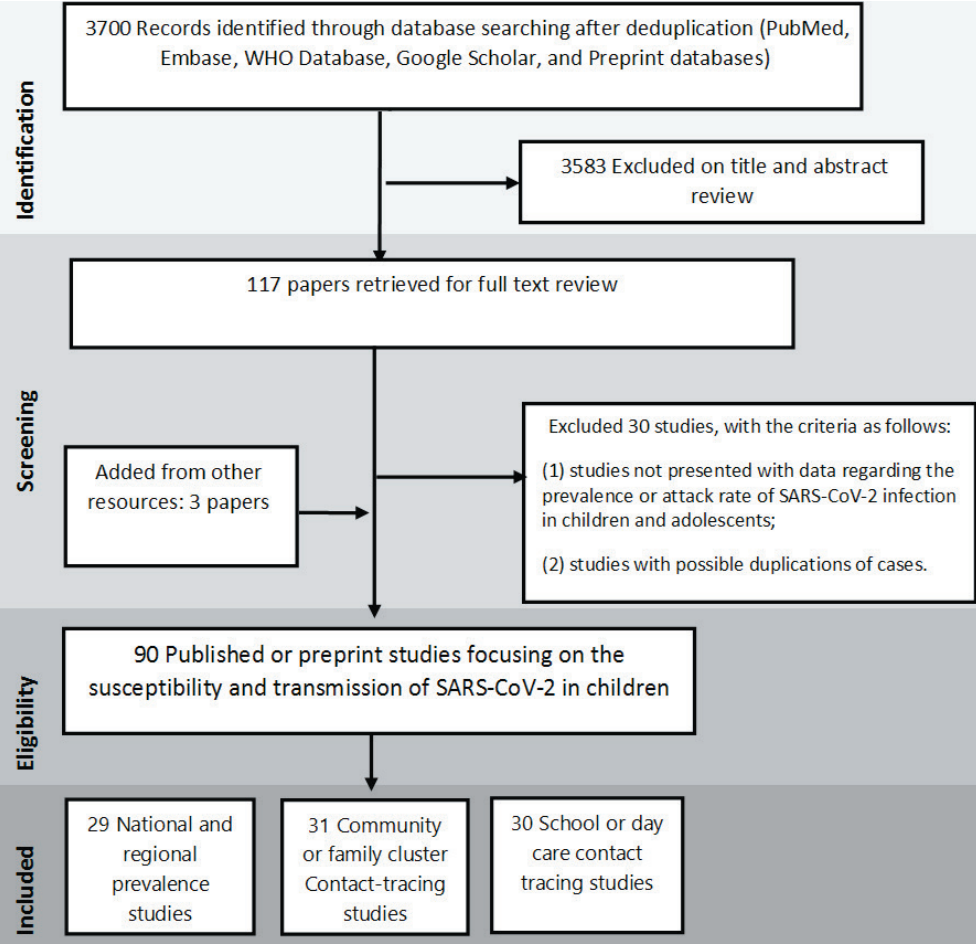

Figure 1. PRISMA flow diagram of study selection process. aggregated data for children, or were commentaries, editorials or reviews with no empirical data.

\section{The overall risk of SARS-Cov-2 infection among children and adolescents in comparison to adults}

To investigate the overall risk of SARS-Cov-2 infection among children and adolescents, we included 60 studies, of which 29 were population-screening studies [19-47] and 31 were CTS [48-78].

The prevalence of COVID-19 in children and adolescents ( $<20$ years of age) were reported in 11 national and 18 subnational surveillance studies. Among them, six were from low- and middle-income countries (LMICs). Compared to adult populations, a comparable risk of SARS-CoV-2 infection was observed in children and adolescents in both national ( $\mathrm{RR}=0.87,95 \% \mathrm{CI}=0.71-1.06)$ and subnational ( $\mathrm{RR}=0.81,95 \% \mathrm{CI}=0.66-1.01)$ surveillance studies, as shown in Figure 2 and Figure 3. When disaggregated by testing methods (ie, RTPCR vs serological test), children and adolescents showed a similar lower risk of past infection from seroprevalence data in national $(\mathrm{RR}=0.77,95 \%$ $\mathrm{CI}=0.62-0.96)$ studies but insignificant effect in subnational studies ( $\mathrm{RR}=0.80,95 \% \mathrm{CI}=0.59-1.08)$. The risk of active infection was lower compared to adults but insignificant in both national studies ( $R R=0.98,95 \%$ $\mathrm{CI}=0.69-1.38)$ and subnational surveillance studies at point estimate level $(\mathrm{RR}=0.77,95 \% \mathrm{CI}=0.48-1.22)$.

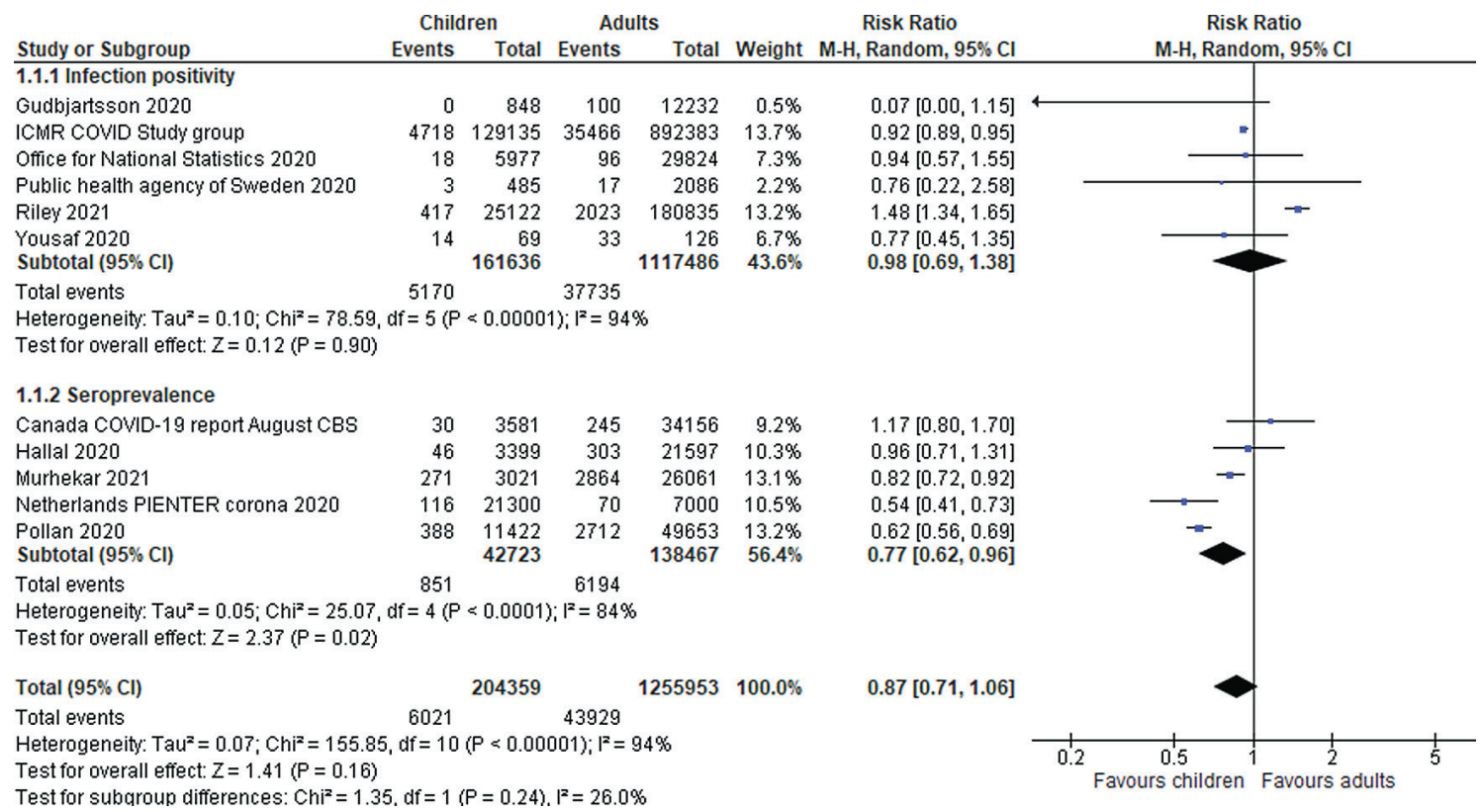

Figure 2. Pooled risk ratio of SARS-Cov-2 infection in children vs adults in national surveillance, disaggregated by infection positivity and seroprevalence.

Thirty-one studies undertook contact-tracing in community, household and family clusters, of which, 12 were from LMICs. The pooled odds of secondary attack in children and adolescents was significantly lower than that in adults $(\mathrm{OR}=0.62,95 \% \mathrm{CI}=0.46-0.84)$, with high heterogeneity $\left(\mathrm{I}^{2}=0.91\right)$ (Figure 4, Panel $\left.\mathrm{A}\right)$. When further disaggregated by the schools' operational status (ie, school closure vs school fully or partially open) during the study period, both children and adolescents were found to have lower risk of infection than did adults when 


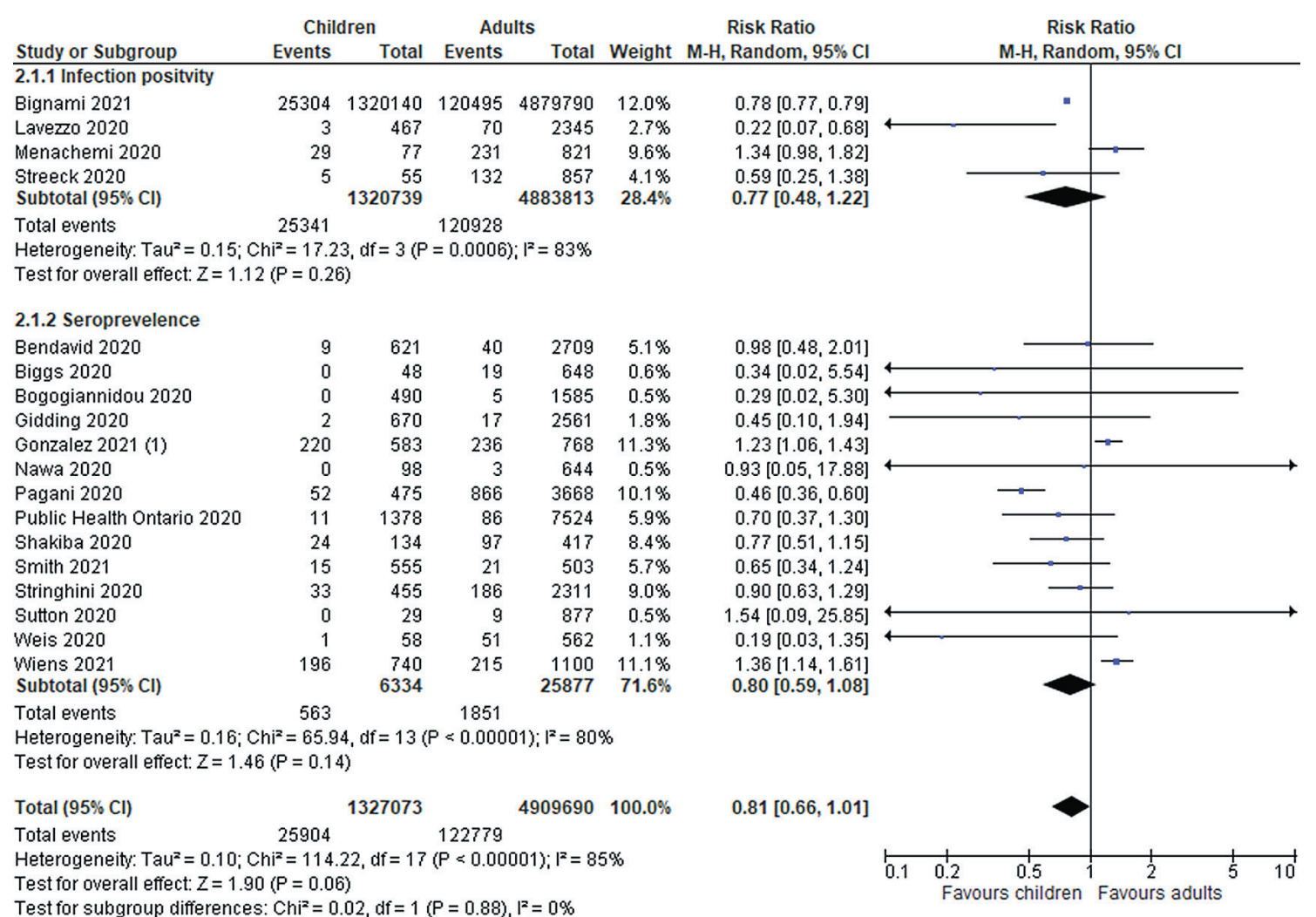

tifferences: $\mathrm{Chi}^{2}=0.02, \mathrm{df}=1(\mathrm{P}=0.88) \mathrm{I}^{2}=0 \%$

Footnotes

(1) children population was $0-15$ years old

Figure 3. Pooled risk ratio of SARS-Cov-2 infection in children vs adults in subnational surveillance, sub-grouped into infection positivity and seroprevalence.

schools were fully or partially open $(\mathrm{OR}=0.52,95 \% \mathrm{CI}=0.33-0.83)$, but no significant effect during school closures (OR=0.72, 95\% CI=0.46-1.14).

In a subgroup analysis of CTS (based on 18 out of the 31 studies) in which age-disaggregation was possible, we found that the pooled OR for SARS-CoV-2 infection among children compared to adults was 0.57 (95\% $\mathrm{CI}=0.37-0.87$ ), suggesting a significantly lower risk of secondary attack in this population at the community and household level. However, a comparable risk of secondary attack was observed among adolescents $(\mathrm{OR}=1.22,95 \% \mathrm{CI}=0.74-2.04)$ (Figure 4, Panel B).

\section{Infection and transmission of COVID-19 among children and adolescents in educational settings compared to adult teachers and staff}

Thirty studies conducted in educational settings were included [12-15,57,79-103], among which six studies were cross-sectional studies and the remaining 24 were contact-tracing or cohort studies. Upon checking the availability of sufficient data for comparison of children vs adults, 24 studies were included in the meta-analysis.

The pooled estimate of the included studies suggested that children and adolescents appeared to have a lower though statistically insignificant risk of secondary attack in school settings when compared to adults $(\mathrm{OR}=0.84$, 95\% $\mathrm{CI}=0.62-1.14$ ) (Figure 5). Subgroup analysis also suggested significant lower odds of infection among children attending daycare centers/preschools $(\mathrm{OR}=0.53,95 \% \mathrm{CI}=0.38-0.72)$, but insignificant effect in primary schools ( $\mathrm{OR}=0.85,95 \% \mathrm{CI}=0.55-1.31)$ compared to the adult staff. However, high-school students had comparable risk of infection to adults $(\mathrm{OR}=1.30,95 \% \mathrm{CI}=0.71-2.38)$.

\section{Risk of contracting SARS-CoV-2 infection among children and adolescents in schools compared to community settings}

Using the existing evidence from both community-based studies and studies conducted in educational settings, we further calculated the pooled odds ratios for contracting infection among children and adolescent in educational settings vs communities and household-clusters. When total number of children and adolescents tested and diagnosed with COVID-19 in the two settings were compared, children observed lower odds of 


Chaw 2020
Dattner 2020
Gupta 2020
Jiang 2020
Kim 2020
Kong 2020
Li 2020
Liu 2020
Luo 2020
Park 2020
Posiay-Barbe 2020
Qifang Bi 2020
Schwart 2020
Wang Y 2020
Wang Z 2020
Zhang (3) 2020
Zhang 2020
Subtotal $(95 \% \mathrm{Cl}$ )
Total events

$\begin{array}{rrrrr}12 & 430 & 39 & 1317 & 4.4 \% \\ 441 & 1738 & 432 & 978 & 5.4 \% \\ 6 & 6 & 7 & 116 & 0.9 \% \\ 1 & 1 & 7 & 11 & 0.7 \% \\ 1 & 78 & 0 & 170 & 0.7 \% \\ 5 & 5 & 11 & 11 & \\ 4 & 100 & 60 & 292 & 3.3 \% \\ 93 & 1867 & 421 & 9713 & 5.4 \% \\ 14 & 357 & 113 & 3053 & 4.6 \% \\ 50 & 694 & 2119 & 58379 & 5.3 \% \\ 0 & 4 & 47 & 57 & 0.8 \% \\ 17 & 233 & 67 & 811 & 4.7 \% \\ 3 & 5 & 8 & 11 & 1.4 \% \\ 13 & 36 & 64 & 92 & 3.9 \% \\ 2 & 10 & 130 & 179 & 2.2 \% \\ 2 & 46 & 10 & 323 & 2.2 \% \\ 47 & 756 & 606 & 6437 & 5.2 \% \\ & 6366 & & 81950 & 51.0 \%\end{array}$

$0.94[0.49,1.81]$ $0.43[0.36,0.51]$ Dattner 2020 Gupta 2020

Kim 2020

Kong 2020

Liu 2020

Posfay-Barbe 2020

Qifang Bi 2020

Wang $Y 2020$

Zhang (3) 202

Subtotal $(95 \%$

311 414

Heterogeneity: $\mathrm{Tau}^{2}=0.51 ; \mathrm{Chi}^{2}=149.87, \mathrm{df}=15(P<0.00001) ; \mathrm{F}^{2}=90 \%$

Test for overall effect: $Z=1.41(P=0.16)$

3.3.2 During schools open/partially open

Atherstone 2021

Cheng 2020

James 2020

Korea Centers for Disease Control and Prevention

Laws 2020

Laxminarayan 2020

Lopez 2020

Maltezou 2020

Metlay 2021

Mizumoto 2020

Rosenberg 2020

Russell 2020

Somekh 2020

van der Hoek 2020

Subtotal ( $95 \%$

Total events
Heterogeneity: $\mathrm{Tau}^{2}=0.53 ; \mathrm{Chi}^{2}=187.41, \mathrm{df}=13(P<0.00001) ; \mathrm{F}^{2}=93 \%$

$\begin{array}{rrrrr}32 & 79 & 9 & 16 & 3.2 \% \\ 1 & 281 & 21 & 2286 & 1.6 \% \\ 2 & 8 & 33 & 37 & 1.7 \% \\ 1 & 155 & 12 & 2201 & 1.5 \% \\ 19 & 68 & 36 & 120 & 4.4 \% \\ 428 & 6075 & 2800 & 42556 & 5.5 \% \\ 13 & 123 & 18 & 92 & 4.0 \% \\ 30 & 43 & 38 & 66 & 3.9 \% \\ 210 & 4672 & 1599 & 13245 & 5.5 \% \\ 10 & 175 & 284 & 2321 & 4.4 \% \\ 42 & 156 & 88 & 182 & 4.9 \% \\ 6 & 39 & 613 & 3672 & 3.8 \% \\ 15 & 58 & 21 & 36 & 3.7 \% \\ 0 & 43 & 55 & 666 & 0.9 \% \\ & 11975 & & 67496 & 49.0 \%\end{array}$

Test for overall effect: $Z=2.73(P=0.006)$

Total $(95 \% \mathrm{Cl})$
Total events
Heterogeneity: Tau $^{2}=0.42 ; \mathrm{Chi}^{2}=337.35, \mathrm{df}=29(\mathrm{P}<0.00001) ; \mathrm{F}^{2}=91 \%$
Test for overall effect: $Z=3.13(P=0.002)$

Test for subaroup differences: $\mathrm{Chi}^{2}=0.96 . \mathrm{df}=1(\mathrm{P}=0.33) . \mathrm{F}^{\mathrm{F}}=0 \%$ $[9.74,3699.75$ $1.80[0.06,54.33]$ $6.60[0.27,163.84]$
Not estimable $0.16[0.06,0.46]$ $1.16[0.92,1.46]$ $1.06[0.60,1.87]$ $2.06[1.54,2.76]$ $0.02[0.00,0.49]$ $0.87[0.50,1.52]$ $0.56[0.06,5.22]$ $0.25[0.11,0.56]$ $0.09[0.02,0.46]$ $1.42[0.30,6.71]$ $0.64[0.47,0.87]$ $0.64[0.47,0.87]$
$0.72[0.46,1.14]$

Figure 4b.

Children

Adults Odds Ratio Study or Subgroup Events Total Events Total Weight M-H, Random, $95 \% \mathrm{Cl}$ $0.53[0.18,1.57]$ $0.39[0.05,2.87]$ $0.04[0.01,0.27]$
$1.18[0.15,9.17]$ $0.90[0.47,1.75]$ $1.08[0.97,1.20]$ $0.49[0.22,1.05]$ $1.70[0.75,3.84]$ $0.34[0.30,0.40]$ $0.43[0.23,0.83]$ $0.39[0.25,0.62]$

$0.91[0.38,2.17]$

$0.25[0.10,0.60]$ $0.13[0.01,2.09]$
$0.52[0.33,0.83]$ 1 Children

Atherstone 2021 Chaw 2020 Dattner 2020 Jiang 2020

Kong 2020

Korea Centers for Disease Control and Prevention

Laws 2020

Laxminarayan 2020

Liu 2020

Lopez 2020

Park 2020

Qifang Bi 2020

Rosenberg 2020

Russell 2020

van der Hoek 2020

Zhang 2020

Subtotal $(95 \% \mathrm{Cl})$

Total events

$\begin{array}{llllll}5 & 8 & 9 & 16 & 2.3 \% & 1.30[0.23,7.38\end{array}$

$\begin{array}{rrrrr}5 & 8 & 9 & 16 & 2.3 \% \\ 4 & 267 & 39 & 1317 & 3.9 \%\end{array}$

$\begin{array}{lllll}149 & 891 & 432 & 978 & 6.0 \%\end{array}$

$\begin{array}{rrrr}1 & 1 & 7 & 11 \\ 4 & 4 & 5 & 5 \\ 0 & 88 & 12 & 2201\end{array}$

5

$0.50[0.18,1.41]$

$0.25[0.20,0.32]$
$1.80[0.06,54.33]$

$1.80[0.06,54.33]$
Not estimable

Not estimable
$0.99[0.06,16.85]$

$0.99[0.06,16.85]$

$\begin{array}{rrrrrr}9 & 44 & 18 & 60 & 4.2 \% & 0.60[0.24,1.50] \\ 40 & 1072 & 2800 & 42556 & 5.8 \% & 0.55[0.40,0.76]\end{array}$

$\begin{array}{llrrr}60 & 1048 & 421 & 9713 & 5.9 \%\end{array}$

$1.34[1.01,1.77]$

$0.49[0.22,1.05]$

$0.57[0.24,1.39]$

$0.89[0.46,1.73]$

$0.27[0.10,0.74]$

$0.33[0.04,2.52]$

$0.17[0.01,2.90]$

$0.64[0.47,0.87]$

$0.57[0.37,0.87]$

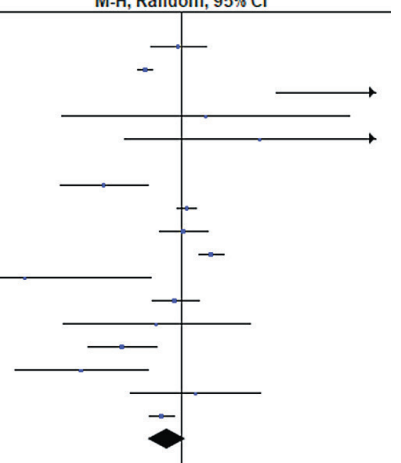

Test for overall effect: $Z=2.60(P=0.009)$
T

3.2.2 Adolescents

Atherstone 2021

Chaw 2020

Dattner 2020

Kim 2020

Kong 2020

Korea Centers for Disease Control and Prevention

Laws 2020

Liu 2020

Liu 2020

Qifang Bi 2020

Russell 2020

van der Hoek 2020

Zhang (3) 2020

Subtotal $(95 \% \mathrm{C})$

Total events

$\begin{array}{rrrrr}1 & 148 & 67 & 811 & 5.0 \%\end{array}$

$\begin{array}{lllll}1 & 16 & 613 & 3672 & 1.9 \%\end{array}$

$\begin{array}{rrrrr}0 & 31 & 55 & 666 & 1.2 \% \\ 47 & 756 & 606 & 6437 & 5.8 \%\end{array}$

354 7309

$\begin{array}{r}6437 \\ 5.8 \% \\ \hline\end{array}$

Test for overall effect: $Z=0.78(P=0.44)$

Total $(95 \% \mathrm{Cl})$

Total events

$\begin{array}{rrrrr}27 & 71 & 9 & 16 & 3.7 \% \\ 8 & 163 & 39 & 1317 & 4.6 \%\end{array}$

9]

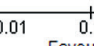

Favours children Favours adults

100

Heterogeneity: Tau $^{2}=0.49 ; \mathrm{Chi}^{2}=215.36, \mathrm{df}=26(P<0.00001) ; \mathrm{I}^{2}=88 \%$

Test for overall effect: $Z=1.34(P=0.18)$

Test for subqroup differences: $\mathrm{Chi}^{2}=5.12, \mathrm{df}=1(\mathrm{P}=0.02) . \mathrm{I}^{2}=80.5 \%$

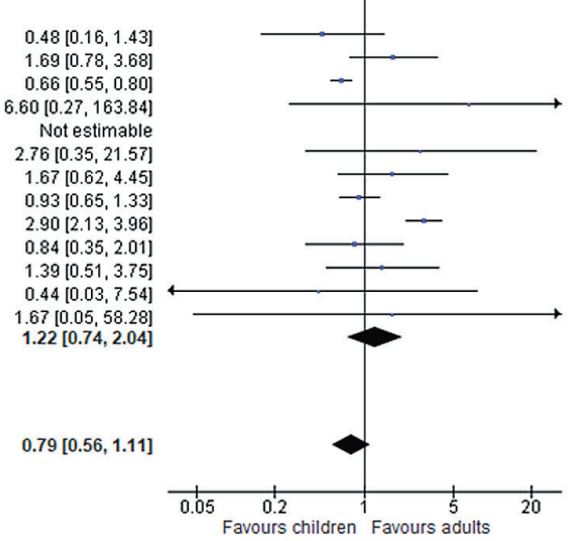

Figure 4. Pooled odds of children and adolescents being an infected contact in community and household family clusters Panel A. Odds of children and adolescents being infected vs adults, by school status. Panel B. Odds of children and adolescents being infected vs adults, by age group (subset of studies in Panel A). 


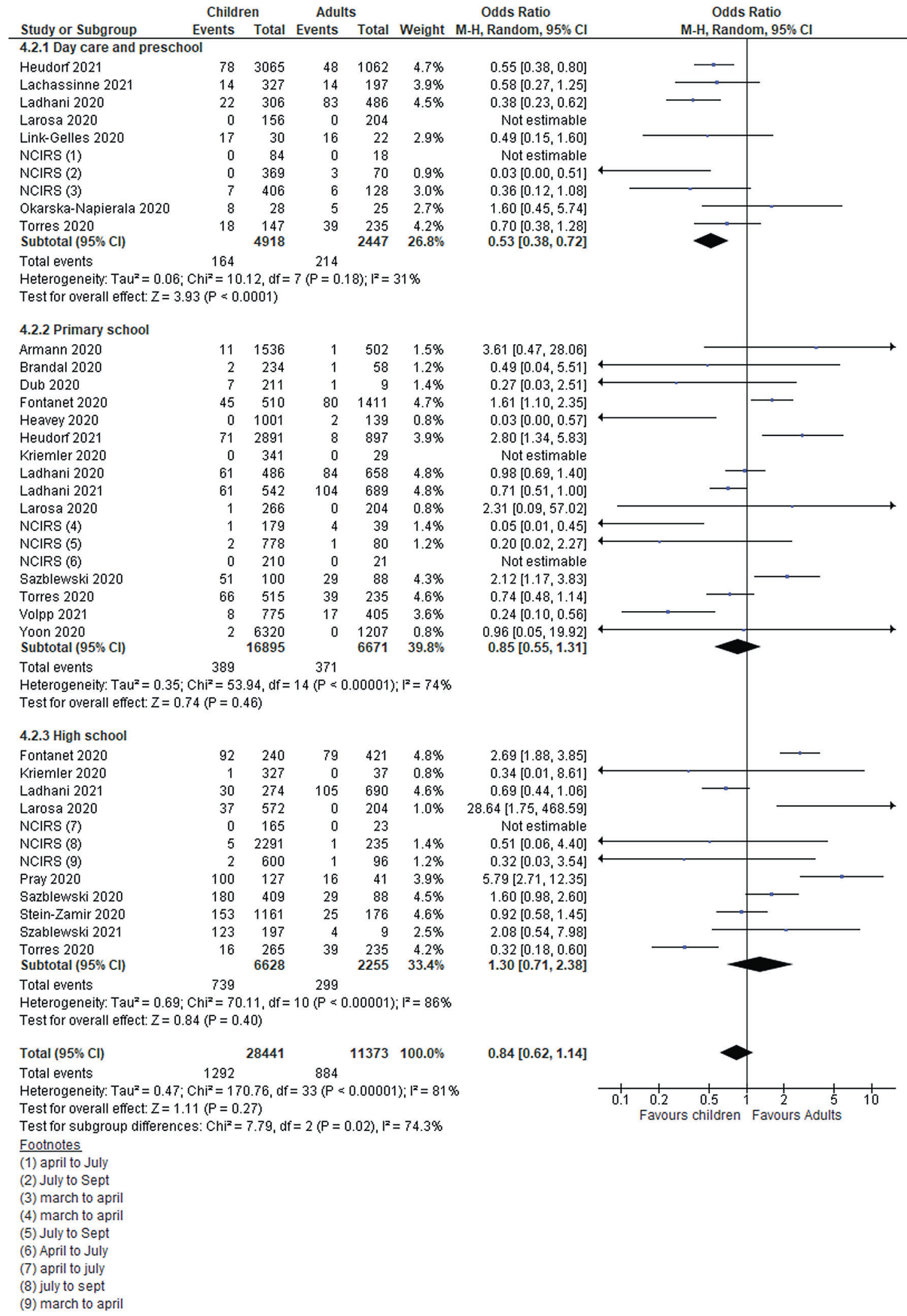

Figure 5. Pooled odds ratios for children and adolescent contracting infection compared to adults, by educational setting.

infection ( $\mathrm{OR}=0.53,95 \% \mathrm{CI}=0.38-0.75)$ in schools compared to community and households, which was consistently observed on disaggregation by age; children ( $<10$ years) $(\mathrm{OR}=0.45,95 \%=0.39-0.51)$; adolescents and high-schoolers ( $\mathrm{OR}=0.63,95 \% \mathrm{CI}=0.56-0.72)$ (Figure $\mathrm{S} 1$ in the Online Supplementary Document). 


\section{Study quality assessment}

The majority of included studies were considered of good or fair quality based on the scores generated by using quality assessment tools (Table S3 in the Online Supplementary Document). Out of the 29 population prevalence studies, 28 were of good quality while one was of fair quality. Twenty-five out of 31 contact-tracing studies were of good quality while six were of fair quality. For studies conducted in educational settings, eight were of fair quality and the remaining 22 were of good quality.

Studies were primarily downgraded for inadequate sample size and unclear description of study setting. However, potential biases were noted for some of the included studies, which could negatively affect their quality (eg, low response rate from the study population in contact-tracing studies $[15,81,83,85]$, only symptomatic cases receiving tests $[12,14,79,86,104])$.

\section{DISCUSSION}

This systematic review provides a comprehensive assessment of COVID-19 risk of infection and transmission in children and adolescents compared to adults in household, community and educational settings and in the relationship of age and school contexts with risks of transmission. Consistent with previous reviews $[105,106]$, we found an overall lower risk of infection among children and adolescents (0-19 years) in households and communities compared to adults. In educational settings, children attending daycare, preschool and primary school presented a lower risk of infection than that of adults.

Our review has several important strengths. Compared to existing reviews [105,106], most of which were conducted at an earlier stage of the pandemic, the present review provided the most up-to-date evidence of this research question. We have undertaken several pre-specified sub-group analyses as per data availability. The subgroup comparisons included assessment of active infection (PCR test), past infection (blood serology), school operational status and differential effects by age groups. It was also important to assess if the risk of community transmission was affected by school closure. Using a broad search strategy implemented in English, Chinese and Spanish databases, we summarize evidence from 90 studies from 31 different countries. We also attempted to reduce possible overlap in cases to prevent duplication. Compared to a previous systematic review by Viner et al [105], we report almost thrice the number of studies with disaggregation of analyses by age and settings. This review is primarily limited by the large heterogeneity across studies and the lack of uniform age- and test-specific evidence for transmission in different study settings. Lastly, the evidence of COVID-19 infection in children is rapidly evolving; therefore, evidence from this review should be cautiously interpreted and regularly updated. This review does not include modelling studies, which can forecast future transmission scenarios but under various assumptions about disease transmission and immunity [107].

Currently available epidemiological data have revealed two unique features of pediatric COVID-19 cases: a relatively low prevalence in this population and milder clinical features compared to adult patients $[9,108]$. Several studies and reviews have studied children and adolescents' susceptibility to SARS-CoV-2 infection and their role in transmission in different settings. Viner et al. examined studies on the prevalence of SARSCoV-2 infection in children and young people ( $<20$ years), and found that the pooled odds ratio of being infected among children vs adults was 0.56 (95\% CI: 0.37-0.85) with substantial heterogeneity $\left(\mathrm{I}^{2}=95 \%\right.$ ) [105]. Goldstein et al [109] reviewed data on detection of SARS-CoV-2 infection in different settings and suggested a significantly lower susceptibility of infection for children ( $<10$ years of age) compared to adults. There was some evidence of robust spread of SARS-CoV-2 in secondary and high-schools (eg, high seroprevalence of anti-SARS-CoV-2 antibodies among high-school students in northern France [83], and an outbreak in an Israel high-school [13]), while the spread seemed to be more limited in primary schools $[12,14,15,82,88-91]$. Xu et al. conducted a living systematic review and reported that the SARS-CoV-2 infection attack rates were 0.15\% (95\% CI=0\%-0.93\%) among students and 0.70\% (95\% CI=0\%-3.56\%) among school staff, respectively [110]. These findings are largely consistent with the primary finding of the present study that children are not as susceptible to SARS-CoV-2 infection as adults, and while children are known to be "super spreaders" for influenza [111] and measles viruses [112], they play only a limited role in SARS-CoV-2 transmission in various settings.

Symptomatic patients have a lower SARS-CoV-2 cycle threshold $(\mathrm{Ct})$ values, which corresponds to higher viral RNA levels. SARS-CoV-2 Ct values have been found to be almost linearly inversely correlated with its transmission [113]. Furthermore, a meta-analysis reported risk of asymptomatic transmission is significantly lower 
than that of symptomatic transmission (relative risk $=0.58 ; 95 \% \mathrm{CI}=0.34-0.99$ ) [114]. To contextualize, these findings might suggest that children may be less likely to transmit SARS-CoV-2 due to their lower prevalence of symptomatic and severe presentation during the infection [115].

School closures are an effective public health mitigation measure in reducing the community transmission of many respiratory infectious diseases, such as influenza [2,3], however, current evidence on the effectiveness of school closures in curbing the COVID-19 pandemic is inconsistent. Large experiences from Australia, USA and England demonstrated low transmission rates in schools and early childhood education services when these facilities were still open $[90,91,116]$. However, Auger et al. conducted a US population-based observational study between March 9 and May 7, 2020 and found that school closure was associated with a significant decline in the incidence of COVID-19 [117]. Majority of the school linked index cases report none or only a small number of secondary cases $[91,93]$. Reports investigating outbreaks have demonstrated a higher transmission by school-age children to other students or teachers, particularly when the mitigation measures were inadequately implemented in schools [104]. Reports from Sweden [118] and US [119] suggest a comparable increased risk of transmission from teacher to students and other staff members. These highlight the significance of focusing COVID-19 prevention protocols and vaccination strategies for the teachers, which may indirectly protect students who might not be immediately prioritized in the vaccine rollout. In the present study, we find overall that opening educational establishments may not predispose children and adolescents to a higher risk of SARS-CoV-2 infection compared to adults. On the contrary, children and adolescents were found to have more than 2-fold greater risk of infection in household and community settings than in schools. The school attendance may serve as a protective factor, which reduces children's chances of community contacts in a relatively isolated environment during school hours. It may also be attributable to the effective infections control measures applied in schools introduced by global and national guidelines.

Importantly, prolonged school closures have also been found to have negative impacts on the educational and social development of children including increasing mental disorders, worsening nutrition, lack of physical activities, substance abuse, child violence and abuse [106,120-124]. Lessons from the 2013-2016 Ebola pandemic suggested that youth, and young girls in particular, of poor households saw the largest increase in permanent school dropouts post-Ebola $[125,126]$. The disruption of education is particularly harmful to young children who are in the most sensitive window of learning, as the early education loss could permanently affect the development of one's foundational skills [127]. Alternative educational opportunities such as online distance learning may not be available to poorer or marginalized populations and are non-existent in many LMICs [128].

The decision to reopen schools is understandably a delicate balance between various factors, including the incidence of COVID-19 cases in the community, the concerns and choices of the parents and the public, the school-based mitigation strategies in place including vaccinations for teachers and the availability of resources. It is recommended that schools should only be reopened when the prevalence of COVID-19 at the community level is under a relatively safe threshold [129].

Safe reopening of schools is not possible without proper mitigation plans and strategies in place. Some of the measures, which are suggested by the present guidelines, include repeat testing, avoiding crowded/close contact environments, social distancing, wearing facial coverings, maintaining hand hygiene, and some protective measure of classrooms and environment, including limiting classroom size and ensuring adequate ventilation including open air classes where feasible [130]. Despite these recommended actions, there are major challenges in evaluating the effectiveness of such guidelines. It is even more challenging to ensure the most effective interventions to be properly implemented in schools. Mitigation strategies at schools may incur a considerable financial cost. For instance, it was estimated that an additional 20 billion USD would be needed for the nationwide implementation of recommended school-based mitigation strategies in the US [131].There is currently limited data on and much need for collating evidence from safe school reopening strategies and experience across the world.

Given the highly contagious nature of SARS-CoV-2 and the new variants, a expanding vaccine eligibility for children and adolescents and addressing it's hesitancy is the most effective strategy for returning children to schools [116]. While some countries have prioritized vaccination of school teachers and staff to reduce occupational transmission, the evidence of effectiveness of vaccination strategies in adolescents is just emerging [132] and trials are being ramped up in younger children [133]. Given the potential serious complications of COVID-19 infection in subsets of children [134], vaccination research and implementation in children must be prioritized across the world. 


Funding: Supported by an unrestricted core grant from UNICEF (NY) through the International Pediatric Association
and core support from the Centre for Global Child Health, Toronto.
Authorship contributions: OI designed the data collection instruments, collected data, carried out data analyses, and
reviewed and revised the manuscript. JL conceptualized and designed the study, conducted the literature search, study
screening, selection and data extraction and drafted the manuscript. KT and ZW drafted the initial manuscript, and re-
viewed and revised the manuscript. ZAB conceptualized and designed the study, coordinated and supervised data collec-
tion, and critically reviewed the manuscript for important intellectual content. All authors approved the final manuscript
as submitted and agree to be accountable for all aspects of the work. ZAB is the guarantor.
Conflict of Interest: The authors have completed the ICMJE Unified Competing Interest form (available on request from
the corresponding author), and declare no conflict of interest
Additional material
Online Supplementary Document

1 World Health Organization. WHO Coronavirus Disease (COVID-19) Dashboard Data last updated: 2021. https://covid19. who.int/. Accessed: 5 April 2021.

2 Viner RM, Russell SJ, Croker H, Packer J, Ward J, Stansfield C, et al. School closure and management practices during coronavirus outbreaks including COVID-19: a rapid systematic review. Lancet Child Adolesc Health. 2020;4:397-404. Medline:32272089 doi:10.1016/S2352-4642(20)30095-X

3 Cauchemez S, Van Kerkhove MD, Archer BN, Cetron M, Cowling BJ, Grove P, et al. School closures during the 2009 influenza pandemic: national and local experiences. BMC Infect Dis. 2014;14:207. Medline:24739814 doi:10.1186/1471-2334-14-207

4 Cauchemez S, Valleron A-J, Boelle P-Y, Flahault A, Ferguson NM. Estimating the impact of school closure on influenza transmission from Sentinel data. Nature. 2008;452:750-4. Medline:18401408 doi:10.1038/nature06732

5 Litvinova M, Liu Q-H, Kulikov ES, Ajelli M. Reactive school closure weakens the network of social interactions and reduces the spread of influenza. Proc Natl Acad Sci U S A. 2019;116:13174-81. Medline:31209042 doi:10.1073/pnas.1821298116

6 Gemmetto V, Barrat A, Cattuto C. Mitigation of infectious disease at school: targeted class closure vs school closure. BMC Infect Dis. 2014;14:695. Medline:25595123 doi:10.1186/s12879-014-0695-9

7 Dong Y, Mo X, Hu Y, Qi X, Jiang F, Jiang Z, et al. Epidemiology of COVID-19 among children in China. Pediatrics. 2020;145:e20200702. doi:10.1542/peds.2020-0702. Medline:32179660

8 CDC COVID-19 Response Team. Coronavirus disease 2019 in children-United States, February 12-April 2, 2020. MMWR Morb Mortal Wkly Rep. 2020;69(14):422-426. Medline:32271728

9 Irfan O, Muttalib F, Tang K, Jiang L, Lassi ZS, Bhutta Z. Clinical characteristics, treatment and outcomes of paediatric COVID-19: a systematic review and meta-analysis. Arch Dis Child. 2021;106:440-8. Medline:33593743 doi:10.1136/archdischild-2020-321385

10 Götzinger F, Santiago-García B, Noguera-Julián A, Lanaspa M, Lancella L, Carducci FIC, et al. COVID-19 in children and adolescents in Europe: a multinational, multicentre cohort study. Lancet Child Adolesc Health. 2020;4:653-61. Medline:32593339 doi:10.1016/S2352-4642(20)30177-2

11 Hoang A, Chorath K, Moreira A, Evans M, Burmeister-Morton F, Burmeister F, et al. COVID-19 in 7780 pediatric patients: a systematic review. EClinicalMedicine. 2020;24:100433. Medline:32766542 doi:10.1016/j.eclinm.2020.100433

12 Heavey L, Casey G, Kelly C, Kelly D, McDarby G. No evidence of secondary transmission of COVID-19 from children attending school in Ireland, 2020. Euro Surveill. 2020;25:2000903. Medline:32489179 doi:10.2807/1560-7917.ES.2020.25.21.2000903

13 Stein-Zamir C, Abramson N, Shoob H, Libal E, Bitan M, Cardash T, et al. A large COVID-19 outbreak in a high school 10 days after schools' reopening, Israel, May 2020. Euro Surveill. 2020;25:2001352. Medline:32720636 doi:10.2807/1560-7917. ES.2020.25.29.2001352

14 Yung CF, Kam K-q, Nadua KD, Chong CY, Tan NWH, Li J, et al. Novel coronavirus 2019 transmission risk in educational settings. Clin Infect Dis. 2021;72:1055-8. Medline:32584975 doi:10.1093/cid/ciaa794

15 Fontanet A, Grant R, Tondeur L, Madec Y, Grzelak L, Cailleau I, et al. SARS-CoV-2 infection in primary schools in northern France: A retrospective cohort study in an area of high transmission. MedRxiv. 2020. doi:10.1101/2020.06.25.20140178.

16 Macartney K, Quinn HE, Pillsbury AJ, Koirala A, Deng L, Winkler N, et al. Transmission of SARS-CoV-2 in Australian educational settings: a prospective cohort study. Lancet Child Adolesc Health. 2020;4:807-16. Medline:32758454 doi:10.1016/ S2352-4642(20)30251-0

17 National Heart L, and Blood Institute. Quality assessment tool for observational cohort and cross-sectional studies. Available: https://www.nhlbi.nih.gov/health-topics/study-quality-assessment-tools. Accessed: 22 February 2021.

18 Institute TJB. Checklist for prevalence studies. Available: https://joannabriggs.org/sites/default/files/2020-08/Checklist_for_ Prevalence_Studies.pdf. Accessed: 22 February 2021.

19 Gudbjartsson DF, Helgason A, Jonsson H, Magnusson OT, Melsted P, Norddahl GL, et al. Spread of SARS-CoV-2 in the Icelandic population. N Engl J Med. 2020;382:2302-15. Medline:32289214 doi:10.1056/NEJMoa2006100

20 Canadian Blood Services. COVID-19 Seroprevalence Report - August 19, 2020. Available: https://www.blood.ca/en/research/ our-research-stories/research-education-discovery/seroprevalence-COVID-19-inside-lab. Accessed: 22 February 2021. 
21 Hallal P, Hartwig F, Horta B, Victora GD, Silveira M, Struchiner C, et al. Remarkable variability in SARS-CoV-2 antibodies across Brazilian regions: nationwide serological household survey in 27 states. MedRxiv. 2020. doi:10.1101/2020.05.30.20117531

22 Yousaf AR, Duca LM, Chu V, Reses HE, Fajans M, Rabold EM, et al. A prospective cohort study in non-hospitalized household contacts with SARS-CoV-2 infection: symptom profiles and symptom change over time. Clin Infect Dis. 2020. Online ahead of print. Medline:32719874 doi:10.1093/cid/ciaal072

23 ICMR COVID Study Group. Laboratory surveillance for SARS-CoV-2 in India: Performance of testing \& descriptive epidemiology of detected COVID-19, January 22-April 30, 2020. Indian J Med Res. 2020;151:424-37. Medline:32611914 doi:10.4103/ ijmr.IJMR_1896_20

24 National Institute for Public Health and the Environment. Children and schools. Available: https://www.rivm.nl/en/novelcoronavirus-covid-19/children-and-covid-19. Accessed: 22 February 2021.

25 Office for National Statistics. Coronavirus (COVID-19) infection survey pilot: England and Wales, 11 September 2020. Available: https://www.ons.gov.uk/peoplepopulationandcommunity/healthandsocialcare/conditionsanddiseases/bulletins/coronaviruscovid19infectionsurveypilot/11september2020. Accessed: 22 February 2021.

26 Pollán M, Pérez-Gómez B, Pastor-Barriuso R, Oteo J, Hernán MA B, Pérez-Olmeda M, et al; ENE-COVID Study Group. Prevalence of SARS-CoV-2 in Spain (ENE-COVID): a nationwide, population-based seroepidemiological study. Lancet. 2020;396:535-44. Medline:32645347 doi:10.1016/S0140-6736(20)31483-5

27 Public Health Agency of Sweden. Förekomsten av covid-19 i Sverige 21-24 april och 25-28 maj 2020. Available: https://www. folkhalsomyndigheten.se/publicerat-material/publikationsarkiv/f/forekomsten-av-covid-19-isverige-21-24-april-och-25-28maj-2020/. Accessed: 28 July 2020.

28 Bendavid E, Mulaney B, Sood N, Shah S, Ling E, Bromley-Dulfano R, et al. Covid-19 antibody seroprevalence in santa clara county, california. MedRxiv. 2020. doi:10.1101/2020.04.14.20062463

29 Biggs HM, Harris JB, Breakwell L, Dahlgren FS, Abedi GR, Szablewski CM, et al. Estimated community seroprevalence of SARS-CoV-2 antibodies-two Georgia counties, April 28-May 3, 2020. MMWR Morb Mortal Wkly Rep. 2020;69:965-70. Medline:32701941 doi:10.15585/mmwr.mm6929e2

30 Bogogiannidou Z, Vontas A, Dadouli K, Kyritsi MA, Soteriades S, Nikoulis DJ, et al. Repeated leftover serosurvey of SARSCoV-2 IgG antibodies, Greece, March and April 2020. Euro Surveill. 2020;25:2001369. Medline:32762796 doi:10.2807/15607917.ES.2020.25.31.2001369

31 Lavezzo E, Franchin E, Ciavarella C, Cuomo-Dannenburg G, Barzon L, Del Vecchio C, et al. Suppression of a SARS-CoV-2 outbreak in the Italian municipality of Vo'. Nature. 2020;584:425-9. Medline:32604404 doi:10.1038/s41586-020-2488-1

32 Menachemi N, Yiannoutsos CT, Dixon BE, Duszynski TJ, Fadel WF, Wools-Kaloustian KK, et al. Population point prevalence of SARS-CoV-2 infection based on a statewide random sample-Indiana, April 25-29, 2020. MMWR Morb Mortal Wkly Rep. 2020;69:960. Medline:32701938 doi:10.15585/mmwr.mm6929e1

33 Nawa N, Kuramochi J, Sonoda S, Yamaoka Y, Nukui Y, Miyazaki Y, et al. Seroprevalence of SARS-CoV-2 IgG Antibodies in Utsunomiya City, Greater Tokyo, after first pandemic in 2020 (U-CORONA): a household-and population-based study. medRxiv. 2020. doi:10.1101/2020.07.20.20155945

34 Pagani G, Conti F, Giacomelli A, Bernacchia D, Rondanin R, Prina A, et al. Seroprevalence of SARS-CoV-2 IgG significantly varies with age: results from a mass population screening (SARS-2-SCREEN-CdA). MedRxiv. 2020. doi:10.1101/2020.06.24 .20138875

35 Public Health Ontario. COVID-19 Serosurveillance Summary. COVID-19 Seroprevalence in Ontario: May 27 to June 30, 2020. Available: https://www.publichealthontario.ca/en/data-and-analysis/infectious-disease/covid-19-data-surveillance. Accessed: 22 February 2021.

36 Shakiba M, Nazemipour M, Salari A, Mehrabian F, Nazari SSH, Rezvani SM, et al. Seroprevalence of SARS-CoV-2 in Guilan Province, Iran, April 2020. Emerg Infect Dis. 2021;27:636. Medline:33349310 doi:10.3201/eid2702.201960

37 Streeck H, Schulte B, Kümmerer BM, Richter E, Höller T, Fuhrmann C, et al. Infection fatality rate of SARS-CoV2 in a super-spreading event in Germany. Nat Commun. 2020;11:5829. Medline:33203887 doi:10.1038/s41467-020-19509-y

38 Stringhini S, Wisniak A, Piumatti G, Azman AS, Lauer SA, Baysson H, et al. Seroprevalence of anti-SARS-CoV-2 IgG antibodies in Geneva, Switzerland (SEROCoV-POP): a population-based study. Lancet. 2020;396:313-9. Medline:32534626 doi:10.1016/ S0140-6736(20)31304-0

39 Sutton M, Cieslak P, Linder M. Notes from the Field: Seroprevalence Estimates of SARS-CoV-2 Infection in Convenience Sample-Oregon, May 11-June 15, 2020. MMWR Morb Mortal Wkly Rep. 2020;69:1100. Medline:32790658 doi:10.15585/ mmwr.mm6932a4

40 Weis S, Scherag A, Baier M, Kiehntopf M, Kamradt T, Kolanos S, et al. Seroprevalence of SARS-CoV-2 antibodies in an entirely PCR-sampled and quarantined community after a COVID-19 outbreak-the CoNAN study. medRxiv. 2020. doi:10.1101/2020.07.15.20154112

41 Riley S, Eales O, Walters CE, Wang H, Ainslie KE, Atchinson C, et al. REACT-1 round 8 final report: high average prevalence with regional heterogeneity of trends in SARS-CoV-2 infection in the community in England during January 2021. medRxiv. 2021. doi:10.1101/2021.01.28.21250606.

42 Bignami-van Assche S, Boujija Y, Fisman D, Sandberg J. In-person schooling and COVID-19 transmission in Canada's three largest cities. medRxiv. 2021. doi:10.1101/2021.03.21.21254064.

43 Murhekar MV, Bhatnagar T, Selvaraju S, Saravanakumar V, Thangaraj JWV, Shah N, et al. SARS-CoV-2 antibody seroprevalence in India, August-September, 2020: findings from the second nationwide household serosurvey. Lancet Glob Health. 2021;9:e257-66. Medline:33515512 doi:10.1016/S2214-109X(20)30544-1 
44 Smith BK, Janowski AB, Danis JE, Harvey IB, Zhao H, Dai Y-N, et al. Seroprevalence of SARS-CoV-2 Antibodies in Children and Adults in St. Louis, Missouri, USA. MSphere. 2021;6:e01207-20. Medline:33536325 doi:10.1128/mSphere.01207-20

45 González F, Vielot NA, Sciaudone M, Toval-Ruíz C, Premkumar L, Gutierrez L, et al. Seroepidemiology of SARS-CoV-2 infections in an urban Nicaraguan population. medRxiv. 2021. doi:10.1101/2021.02.25.21252447.

46 Gidding HF, Machalek DA, Hendry AJ, Quinn HE, Vette K, Beard FH, et al. Seroprevalence of SARS-CoV-2-specific antibodies in Sydney, Australia following the first epidemic wave in 2020. Med J Aust. 2021;214:179-85. Medline:33538019 doi:10.5694/ mja2.50940

47 Wiens KE, Mawien PN, Rumunu J, Slater D, Jones FK, Moheed S, et al. Seroprevalence of anti-SARS-CoV-2 IgG antibodies in Juba, South Sudan: a population-based study. medRxiv. 2021. doi:10.1101/2021.03.08.21253009.

48 Chaw L, Koh W, Jamaludin S, Naing L, Alikhan M, Wong J. SARS-CoV-2 transmission in different settings: Analysis of cases and close contacts from the Tablighi cluster in Brunei Darussalam. medRxiv. 2020. doi:10.1101/2020.05.04.20090043.

49 Cheng H-Y, Jian S-W, Liu D-P, Ng T-C, Huang W-T, Lin H-H. Contact tracing assessment of COVID-19 transmission dynamics in Taiwan and risk at different exposure periods before and after symptom onset. JAMA Intern Med. 2020;180:1156-63. Medline:32356867 doi:10.1001/jamainternmed.2020.2020

50 Dattner I, Goldberg Y, Katriel G, Yaari R, Gal N, Miron Y, et al. The role of children in the spread of COVID-19: Using household data from Bnei Brak, Israel, to estimate the relative susceptibility and infectivity of children. PLOS Comput Biol. 2021;17:e1008559. Medline:33571188 doi:10.1371/journal.pcbi.1008559

51 James A, Eagle L, Phillips C, Hedges DS, Bodenhamer C, Brown R, et al. High COVID-19 attack rate among attendees at events at a church-Arkansas, March 2020. MMWR Morb Mortal Wkly Rep. 2020;69:632-635.

52 Jiang Y, Niu W, Wang Q, Zhao H, Meng L, Zhang C. Characteristics of a family cluster of severe acute respiratory syndrome coronavirus 2 in Henan, China. J Infect. 2020;81:e46-8. Medline:32335170 doi:10.1016/j.jinf.2020.04.028

53 COVID-19 National Emergency Response Center, Epidemiology and Case Management Team, Korea Centers for Disease Control and Prevention. Coronavirus Disease-19: Summary of 2,370 Contact Investigations of the First 30 Cases in the Republic of Korea. Osong Public Health Res Perspect. 2020;11:81-4. Medline:32257773 doi:10.24171/j.phrp.2020.11.2.04

54 Laxminarayan R, Wahl B, Dudala SR, Gopal K, Neelima S, Reddy KJ, et al. Epidemiology and transmission dynamics of COVID-19 in two Indian states. Science. 2020;370:691-7. Medline:33154136 doi:10.1126/science.abd7672

55 Li W, Zhang B, Lu J, Liu S, Chang Z, Peng C, et al. Characteristics of household transmission of COVID-19. Clin Infect Dis. 2020;71:1943-6. Medline:32301964 doi:10.1093/cid/ciaa450

56 Liu T, Liang W, Zhong H, He J, Chen Z, He G, et al. Risk factors associated with COVID-19 infection: a retrospective cohort study based on contacts tracing. Emerg Microbes Infect. 2020;9:1546-53. Medline:32608325 doi:10.1080/22221751.2020.1787799

57 Lopez AS, Hill M, Antezano J, Vilven D, Rutner T, Bogdanow L, et al. Transmission dynamics of COVID-19 outbreaks associated with child care facilities—Salt Lake City, Utah, April-July 2020. MMWR Morb Mortal Wkly Rep. 2020;69:1319. Medline:32941418 doi:10.15585/mmwr.mm6937e3

58 Mizumoto K, Omori R, Nishiura H. Age specificity of cases and attack rate of novel coronavirus disease (COVID-19). MedRxiv. 2020. doi:10.1101/2020.03.09.20033142.

59 Park YJ, Choe Y, Park O, Park S, Kim Y, Kim J, et al. COVID-19 National Emergency Response Center, Epidemiology and Case Management Team. Contact tracing during coronavirus disease outbreak, South Korea, 2020. Emerg Infect Dis. 2020;26:24658. Medline:32673193 doi:10.3201/eid2610.201315

60 Posfay-Barbe KM, Wagner N, Gauthey M, Moussaoui D, Loevy N, Diana A, et al. COVID-19 in children and the dynamics of infection in families. Pediatrics. 2020;146:e20201576. Medline:32457213 doi:10.1542/peds.2020-1576

61 Rosenberg ES, Dufort EM, Blog DS, Hall EW, Hoefer D, Backenson BP, et al. COVID-19 testing, epidemic features, hospital outcomes, and household prevalence, New York State-March 2020. Clin Infect Dis. 2020;71:1953-9. Medline:32382743 doi:10.1093/cid/ciaa549

62 Fore HH, Dongyu Q, Beasley DM, Ghebreyesus TA. Child malnutrition and COVID-19: the time to act is now. Lancet. 2020;396:517-8. Medline:32730742 doi:10.1016/S0140-6736(20)31648-2

63 World Food Programme. COVID-19 will double number of people facing food crises unless swift action is taken. 2020. Available: https://www.wfp.org/news/covid-19-will-double-number-people-facing-food-crises-unlessswift-action-taken. Accessed: 22 February 2021.

64 UNICEF. Situation tracking for COVID-19 socio-economic impacts. New York: UNICEF. 2020. Available: https://data.unicef. org/resources/rapid-situation-tracking-covid-19-socioeconomic-impacts-data-viz/. Accessed: 22 February 2021.

65 UNICEF. Yemeni children face deadly hunger and aid shortages as COVID-19 pandemic spreads - UNICEF. 26 June, 2020. Available: https://www.unicef.org/press-releases/yemeni-children-face-deadly-hunger-and-aid-shortages-covid-19-pandemicspreads. Accessed: 22 February 2021.

66 World Health Organization. Addressing violence against children, women and older people during the COVID-19 pandemic: key actions, 17 June 2020. Geneva: WHO; 2020.

67 World Health Organization. Nurturing care for early childhood development: a framework for helping children survive and thrive to transform health and human potential. Geneva: WHO; 2018.

68 Komorowski M, Aberegg SK. Using applied lung physiology to understand COVID-19 patterns. Br J Anaesth. 2020;125:2503. Medline:32536444 doi:10.1016/j.bja.2020.05.019

69 Xie J, Covassin N, Fan Z, Singh P, Gao W, Li G, et al, editors. Association between hypoxemia and mortality in patients with COVID-19. Mayo Clin Proc. 2020;95:1138-47. Medline:32376101 doi:10.1016/j.mayocp.2020.04.006

70 Wang Y, Tian H, Zhang L, Zhang M, Guo D, Wu W, et al. Reduction of secondary transmission of SARS-CoV-2 in households by face mask use, disinfection and social distancing: a cohort study in Beijing, China. BMJ Glob Health. 2020;5:e002794. Medline:32467353 doi:10.1136/bmjgh-2020-002794 
71 Gupta N, Saravu K, Varma M, Pm A, Shetty S, Umakanth S. Transmission of SARS-CoV-2 Infection by Children: A Study of Contacts of Index Paediatric Cases in India. J Trop Pediatr. 2021;67:fmaa081. Medline:33280033 doi:10.1093/tropej/fmaa081

72 Kim J, Choe YJ, Lee J, Park YJ, Park O, Han MS, et al. Role of children in household transmission of COVID-19. Archives of disease in childhood. 2020; archdischild-2020-319910. Medline:32769089 doi:10.1136/archdischild-2020-319910

73 Kong X-G, Geng J, Zhang T, Wang B, Wu A-Z, Xiao D, et al. Dynamic profiles of SARS-Cov-2 infection from five Chinese family clusters in the early stage of the COVID-19 pandemic. Sci Rep. 2020;10:22048. Medline:33328533 doi:10.1038/s41598020-79035-1

74 Luo L, Liu D, Liao X, Wu X, Jing Q, Zheng J, et al. Contact settings and risk for transmission in 3410 close contacts of patients with COVID-19 in Guangzhou, China: a prospective cohort study. Ann Intern Med. 2020;173:879-87. Medline:32790510 doi:10.7326/M20-2671

75 Bi Q, Wu Y, Mei S, Ye C, Zou X, Zhang Z, et al. Epidemiology and transmission of COVID-19 in 391 cases and 1286 of their close contacts in Shenzhen, China: a retrospective cohort study. Lancet Infect Dis. 2020;20:911-9. Medline:32353347 doi:10.1016/S1473-3099(20)30287-5

76 Metlay JP, Haas JS, Soltoff AE, Armstrong KA. Household Transmission of SARS-CoV-2. JAMA Network Open. 2021;4:e210304. Medline:33635324 doi:10.1001/jamanetworkopen.2021.0304

77 Maltezou HC, Vorou R, Papadima K, Kossyvakis A, Spanakis N, Gioula G, et al. Transmission dynamics of SARS-CoV-2 within families with children in Greece: A study of 23 clusters. J Med Virol. 2021;93:1414-20. Medline:32767703 doi:10.1002/ jmv.26394

78 Atherstone C, Siegel M, Schmitt-Matzen E, Sjoblom S, Jackson J, Blackmore C, et al. SARS-CoV-2 transmission associated with high school wrestling tournaments_Florida, December 2020-January 2021. MMWR Morb Mortal Wkly Rep. 2021;70:141. Medline:33507895 doi:10.15585/mmwr.mm7004e4

79 Szablewski CM, Chang KT, Brown MM, Chu VZ, Yousaf AR, Anyalechi N, et al. SARS-CoV-2 Transmission and Infection Among Attendees of an Overnight Camp - Georgia, June 2020. MMWR Morb Mortal Wkly Rep. 2020;69:1023-5. Medline:32759921 doi:10.15585/mmwr.mm6931e1

80 Desmet S, Ekinci E, Wouters I, Decru B, Beuselinck K, Malhotra-Kumar S, et al. No SARS-CoV-2 carriage observed in children attending daycare centers during the intial weeks of the epidemic in Belgium. J Med Virol. 2021;93:1828-31. Medline:33230857 doi:10.1002/jmv.26689

81 Torres JP, Piñera C, De La Maza V, Lagomarcino AJ, Simian D, Torres B, et al. SARS-CoV-2 antibody prevalence in blood in a large school community subject to a Covid-19 outbreak: a cross-sectional study. Clinical Infectious Diseases. 2020; ciaa955. Medline:32649743

82 Dub T, Erra E, Hagberg L, Sarvikivi E, Virta C, Jarvinen A, et al. Transmission of SARS-CoV-2 following exposure in school settings: experience from two Helsinki area exposure incidents. medRxiv. 2020. doi:10.1101/2020.07.20.20156018.

83 Fontanet A, Tondeur L, Madec Y, Grant R, Besombes C, Jolly N, et al. Cluster of COVID-19 in northern France: A retrospective closed cohort study. medRxiv. 2020. doi:10.1101/2020.04.18.20071134.

84 Armann JP, Unrath M, Kirsten C, Lück C, Dalpke A, Berner R. Anti-SARS-CoV-2 IgG antibodies in adolescent students and their teachers in Saxony, Germany (SchoolCoviDD19): very low seropraevalence and transmission rates. 2020. doi:10.1101 /2020.07.16.20155143

85 Brown NE, Bryant-Genevier J, Bandy U, Browning CA, Berns AL, Dott M, et al. Antibody responses after classroom exposure to teacher with coronavirus disease, March 2020. Emerg Infect Dis. 2020;26:2263. Medline:32597750 doi:10.3201/ eid2609.201802

86 Blaisdell LL, Cohn W, Pavell JR, Rubin DS, Vergales JE. Preventing and mitigating SARS-CoV-2 transmission—four overnight camps, Maine, June-August 2020. MMWR Morb Mortal Wkly Rep. 2020;69:1216-20. Medline:32881850 doi:10.15585/ mmwr.mm6935e1

87 Link-Gelles R, DellaGrotta AL, Molina C, Clyne A, Campagna K, Lanzieri TM, et al. Limited secondary transmission of SARSCoV-2 in child care programs—Rhode Island, June 1-July 31, 2020. MMWR Morb Mortal Wkly Rep. 2020;69:1170-2. Medline:32853185 doi:10.15585/mmwr.mm6934e2

88 Surveillance NCIRS. COVID-19 in schools and early childhood education and care services-The term 1 experience in NSW. National Centre for Immunisazion Research and Surveillance (NCIRS); July 31, 2020 2020. Available: https://www.ncirs.org. au/covid-19-in-schools. Accessed: 22 February 2021.

89 Surveillance NCIRS. COVID-19 in schools and early childhood education and care services-The term 2 experience in NSW. National Centre for Immunisazion Research and Surveillance (NCIRS); July 31, 2020 2020. Available: https://www.ncirs.org. au/covid-19-in-schools. Accessed: 22 February 2021.

90 Surveillance NCIRS. COVID-19 in schools and early childhood education and care services-The term 3 experience in NSW. National Centre for Immunisazion Research and Surveillance (NCIRS); July 31, 2020 2020. Available: https://www.ncirs.org. au/covid-19-in-schools. Accessed: 22 February 2021.

91 Ismail SA, Saliba V, Bernal JL, Ramsay ME, Ladhani SN. SARS-CoV-2 infection and transmission in educational settings: a prospective, cross-sectional analysis of infection clusters and outbreaks in England. Lancet Infect Dis. 2021;21:344-53. Medline:33306981 doi:10.1016/S1473-3099(20)30882-3

92 Brandal LT, Ofitserova TS, Meijerink H, Rykkvin R, Lund HM, Hungnes O, et al. Minimal transmission of SARS-CoV-2 from paediatric COVID-19 cases in primary schools, Norway, August to November 2020. Euro Surveill. 2021;26:2002011. Medline:33413743 doi:10.2807/1560-7917.ES.2020.26.1.2002011

93 Larosa E, Djuric O, Cassinadri M, Cilloni S, Bisaccia E, Vicentini M, et al. Secondary transmission of COVID-19 in preschool and school settings in northern Italy after their reopening in September 2020: a population-based study. Euro Surveill. 2020;25:2001911. Medline:33303065 doi:10.2807/1560-7917.ES.2020.25.49.2001911 
94 Yoon Y, Kim K-R, Park H. young Kim S, Kim Y-J. Stepwise school opening online and off-line and an impact on the epidemiology of COVID-19 in the pediatric population. medRxiv. 2020. doi:10.1101/2020.08.03.20165589.

95 Okarska-Napierała M, Mańdziuk J, Kuchar E. SARS-CoV-2 Cluster in Nursery, Poland. Emerg Infect Dis. 2021;27:317. Medline:33035153 doi:10.3201/eid2701.203849

96 Kriemler S, Ulyte A, Ammann P, Peralta GP, Berger C, Puhan MA, et al. Surveillance of acute SARS-CoV-2 infections in school children and point-prevalence during a time of high community transmission in Switzerland. medRxiv. 2021. doi:10.1101 /2020.12.24.20248558.

97 Ulyte A, Radtke T, Abela IA, Haile SR, Berger C, Huber M, et al. Clustering and longitudinal change in SARS-CoV-2 seroprevalence in school-children: prospective cohort study of 55 schools in Switzerland. BMJ. 2021.372:n616. Medline:33731327 doi:10.1136/bmj.n616

98 Ladhani S. Prospective Active National Surveillance of Preschools and Primary Schools for SARS-CoV-2 Infection and Transmission in England. SSRN, June 2020. Available: https://papers.ssrn.com/sol3/papers.cfm?abstract_id=3764198. Accessed: 22 February 2021.

99 Ladhani SN, Baawuah F, Beckmann J, Okike IO, Ahmad S, Garstang J, et al. SARS-CoV-2 infection and transmission in primary schools in England in June-December, 2020 (sKIDs): an active, prospective surveillance study. Lancet Child Adolesc Health. 2021;5:417-27. Medline:33740430 doi:10.1016/S2352-4642(21)00061-4

100 Szablewski CM, Chang KT, McDaniel CJ, Chu VT, Yousaf AR, Schwartz NG, et al. SARS-CoV-2 transmission dynamics in a sleep-away camp. Pediatrics. 2021;147:e2020046524. Medline:33504612 doi:10.1542/peds.2020-046524

101 Lachassinne E, de Pontual L, Caseris M, Lorrot M, Guilluy C, Naud A, et al. SARS-CoV-2 transmission among children and staff in daycare centres during a nationwide lockdown in France: a cross-sectional, multicentre, seroprevalence study. Lancet Child Adolesc Health. 2021;5:256-64. Medline:33571450 doi:10.1016/S2352-4642(21)00024-9

102 Heudorf U, Steul K, Walczok A, Gottschalk R. Children and COVID-19-Data from mandatory reporting and results of contact person testing in daycare centers and schools in Frankfurt am Main, Germany. Monatsschrift Kinderheilkunde. 2021;2021:111. Medline:33678906

103 Volpp KG, Kraut BH, Ghosh S, Neatherlin J. Minimal SARS-CoV-2 Transmission After Implementation of a Comprehensive Mitigation Strategy at a School—New Jersey, August 20-November 27, 2020. MMWR Morb Mortal Wkly Rep. 2021;70:377. Medline:33735161 doi:10.15585/mmwr.mm701la2

104 Pray IW, Gibbons-Burgener SN, Rosenberg AZ, Cole D, Borenstein S, Bateman A, et al. COVID-19 Outbreak at an Overnight Summer School Retreat_Wisconsin, July-August 2020. MMWR Morb Mortal Wkly Rep. 2020;69:1600. Medline:33119558 doi:10.15585/mmwr.mm6943a4

105 Viner RM, Mytton OT, Bonell C, Melendez-Torres G, Ward J, Hudson L, et al. Susceptibility to SARS-CoV-2 infection among children and adolescents compared with adults: a systematic review and meta-analysis. JAMA Pediatr. 2021;175:143-56. Medline:32975552 doi:10.1001/jamapediatrics.2020.4573

106 Merckx J, Labrecque JA, Kaufman JS. Transmission of SARS-CoV-2 by children. Dtsch Arztebl Int. 2020;117:553. Medline:32705983

107 Lu FS, Nguyen AT, Link NB, Lipsitch M, Santillana M. Estimating the early outbreak cumulative incidence of COVID-19 in the United States: three complementary approaches. medRxiv. 2020.

108 Castagnoli R, Votto M, Licari A, Brambilla I, Bruno R, Perlini S, et al. Severe acute respiratory syndrome coronavirus 2 (SARS-CoV-2) infection in children and adolescents: a systematic review. JAMA Pediatr. 2020;174:882-9. Medline:32320004 doi:10.1001/jamapediatrics.2020.1467

109 Goldstein E, Lipsitch M, Cevik M. On the Effect of Age on the Transmission of SARS-CoV-2 in Households, Schools, and the Community. J Infect Dis. 2021;223:362-9. Medline:33119738 doi:10.1093/infdis/jiaa691

$110 \mathrm{Xu}$ W, Li X, Dozier M, He Y, Kirolos A, Lang Z, et al. What is the evidence for transmission of COVID-19 by children in schools? A living systematic review. J Glob Health. 2020;10:021104. Medline:33437465 doi:10.7189/jogh.10.021104

111 Tsang TK, Fang VJ, Chan K-H, Ip DK, Leung GM, Peiris JM, et al. Individual correlates of infectivity of influenza A virus infections in households. PLoS One. 2016;11:e0154418. Medline:27153194 doi:10.1371/journal.pone.0154418

112 Paunio M, Peltola H, Valle M, Davidkin I, Virtanen M, Heinonen OP. Explosive school-based measles outbreak: intense exposure may have resulted in high risk, even among revaccinees. Am J Epidemiol. 1998;148:1103-10. Medline:9850133 doi:10.1093/oxfordjournals.aje.a009588

113 Lyngse FP, Mølbak K, Træholt Frank K, Nielsen C, Skov RL, Kirkeby CT. Association between SARS-CoV-2 transmission risk, viral load, and age: a nationwide study in Danish households. medRxiv. doi:10.1101/2021.02.28.21252608.

114 Byambasuren O, Cardona M, Bell K, Clark J, McLaws M-L, Glasziou P. Estimating the extent of asymptomatic COVID-19 and its potential for community transmission: systematic review and meta-analysis. JAMMI. 2020;5:223-34. doi:10.3138/ jammi-2020-0030

115 Rostad CA, Kamidani S, Anderson EJ. Implications of SARS-CoV-2 Viral Load in Children: Getting Back to School and Normal. JAMA Pediatr. 2021. Epub ahead of print. Medline:34115097 doi:10.1001/jamapediatrics.2021.2022

116 Zimmerman KO, Akinboyo IC, Brookhart MA, Boutzoukas AE, McGann K, Smith MJ, et al. Incidence and secondary transmission of SARS-CoV-2 infections in schools. Pediatrics 2021. Epub ahead of print. Medline:33419869 doi:10.1542/ peds.2020-048090.

117 Auger KA, Shah SS, Richardson T, Hartley D, Hall M, Warniment A, et al. Association between statewide school closure and COVID-19 incidence and mortality in the US. JAMA. 2020;324:859-70. Medline:32745200 doi:10.1001/jama.2020.14348

118 Vlachos J, Hertegård E, Svaleryd HB. The effects of school closures on SARS-CoV-2 among parents and teachers. Proc Natl Acad Sci U S A. 2021;118:e2020834118. Medline:33574041 doi:10.1073/pnas.2020834118 
119 Gold JA. Clusters of SARS-CoV-2 infection among elementary school educators and students in one school district-Georgia, December 2020-January 2021. MMWR Morb Mortal Wkly Rep. 2021;70:289-92. Medline:33630823 doi:10.15585/ mmwr.mm7008e4

120 Ziauddeen N, Woods-Townsend K, Saxena S, Gilbert R, Alwan NA. Schools and COVID-19: reopening Pandora's Box? Public Health in Practice. 2020;1:100039. doi:10.1016/j.puhip.2020.100039

121 Van Lancker W, Parolin Z. COVID-19, school closures, and child poverty: a social crisis in the making. Lancet Public Health. 2020;5:e243-4. Medline:32275858 doi:10.1016/S2468-2667(20)30084-0

122 Xie X, Xue Q, Zhou Y, Zhu K, Liu Q, Zhang J, et al. Mental health status among children in home confinement during the coronavirus disease 2019 outbreak in Hubei Province, China. JAMA Pediatr. 2020;174:898-900. Medline:32329784 doi:10.1001/jamapediatrics.2020.1619

123 Wang G, Zhang Y, Zhao J, Zhang J, Jiang F. Mitigate the effects of home confinement on children during the COVID-19 outbreak. Lancet. 2020;395:945-47. Medline:32145186 doi:10.1016/S0140-6736(20)30547-X

124 Dunn CG, Kenney E, Fleischhacker SE, Bleich SN. Feeding low-income children during the Covid-19 pandemic. N Engl J Med. 2020;382:e40. Medline:32227759 doi:10.1056/NEJMp2005638

125 Hallgarten J. Evidence on efforts to mitigate the negative educational impact of past disease outbreaks. 2020 Report 793. Reading, UK: Education Development Trust. 2020.

126 Government of Sierra Leone. National Ebola Recovery Strategy for Sierra Leone: 2015-2017. Freetown: Government of Sierra Leone; 2015.

127 Conto CA, Akseer S, Dreesen T, Kamei A, Mizunoya S, Rigole A, et al. COVID-19: Effects of school closures on foundational skills and promising practices for monitoring and mitigating learning loss. 2020. Available: https://www.unicef-irc.org/publications/1144-covid19-effects-of-school-closures-on-foundational-skills-and-promising-practices.html. Accessed: 22 February 2021.

128 Eltahir ME. E-learning in developing countries: Is it a panacea? A case study of Sudan. IEEE Access. 2019;7:97784-92. doi:10.1109/ACCESS.2019.2930411

129 Levinson M, Cevik M, Lipsitch M. Reopening primary schools during the pandemic. N Engl J Med. 2020;383:981-5. Medline:32726550 doi:10.1056/NEJMms2024920

130 Coronado F, Blough S, Bergeron D, Proia K, Sauber-Schatz E, Beltran M, et al. Implementing mitigation strategies in early care and education settings for prevention of SARS-CoV-2 transmission—eight states, September-October 2020. MMWR Morb Mortal Wkly Rep. 2020;69:1868. Medline:33301431 doi:10.15585/mmwr.mm6949e3

131 National Academies of Sciences E. Medicine. Reopening K-12 schools during the Covid-19 pandemic: Prioritizing health, equity, and communities: National Academies Press; 2020. Available: https://www.nap.edu/catalog/25858/reopening-k-12schools-during-the-covid-19-pandemic-prioritizing. Accessed: 22 February 2021.

132 Pfizer-BioNTech Announce Positive Topline Results of Pivotal COVID-19 Vaccine Study in Adolescents. March 31, 2021. Available: https://www.pfizer.com/news/press-release/press-release-detail/pfizer-biontech-announce-positive-topline-results-pivotal. Accessed: 22 February 2021.

133 Couzin-Frankel J. Vaccine trials ramp up in children and adolescents. Science. 2021;371:874-5. Medline:33632828 doi:10.1126/science.371.6532.874

134 Jiang L, Tang K, Levin M, Irfan O, Morris SK, Wilson K, et al. COVID-19 and multisystem inflammatory syndrome in children and adolescents. Lancet Infect Dis. 2020;20:e276-e288. Medline:32818434 doi:10.1016/S1473-3099(20)30651-4 